\title{
Infection with hepatitis viruses, FIB-4 index and risk of hepatocellular carcinoma in southern Italy: a population-based cohort study
}

Mario Fusco ${ }^{1 \dagger}$, Pierluca Piselli ${ }^{2 \dagger}$, Saverio Virdone ${ }^{3}$, Pietro Di Cicco ${ }^{4}$, Paola Scognamiglio ${ }^{2}$, Paolo De Paoli ${ }^{5}$, Valerio Ciullo ${ }^{1}$, Diana Verdirosi ${ }^{3}$, Michele D'Orazio ${ }^{4}$, Luigino Dal Maso ${ }^{3}$, Enrico Girardi ${ }^{2}$, Silvia Franceschi ${ }^{6}$ and Diego Serraino ${ }^{3^{*}}$ (D)

\begin{abstract}
Background: The incidence of hepatocellular carcinoma (HCC) and its association with hepatitis $\mathrm{C}(\mathrm{HCV})$ and hepatitis B virus (HBV) infections, FIB-4 index and liver enzymes was assessed in an area of the province of Naples covered by a population-based cancer registry.

Methods: We conducted a cohort investigation on 4492 individuals previously enrolled in a population-based seroprevalent survey on HCV and HBV infections. The diagnosis of HCC was assessed through a record linkage with the cancer registry. Hepatic metabolic activity was measured through serum alanine transaminase, aspartate aminotransferase, gamma-glutamyl-transferase, and platelet. The FIB-4 index was used as a marker of fibrosis. We computed HCC incidence rates (IR) for 100,000 $\left(10^{5}\right)$ person-years of observation, and multivariable hazard ratios (HR) with $95 \%$ confidence intervals (Cl) to assess risk factors for HCC.

Results: Twenty two cases of HCC were diagnosed during follow-up (IR $=63.3$ cases $\left./ 10^{5}\right)$. Significantly increased HCC risks were documented in individuals with higher than normal liver enzymes and low platelet count; in the 239 HCV RNA-positives ( $\mathrm{HR}=61.8,95 \% \mathrm{Cl}: 13.3-286)$; and in the $95 \mathrm{HBsAg}$-positives ( $\mathrm{HR}=75.0)$-as compared to uninfected individuals. The highest FIB-4 score was associated with a 17.6-fold increased HCC risk.

Conclusions: An elevated FIB-4 index turned out to be an important predictor of HCC occurrence. Although the standard method to assess hepatic fibrosis in chronic hepatitis remains the histologic staging of liver biopsy specimen, the assessment of FIB-4 in HCV RNA-positive individuals may help in identifying the highest HCC-risk individuals who need anti-HCV treatment most urgently.
\end{abstract}

Keywords: Liver diseases, Relative risk, Epidemiology, Viral hepatitis, Liver fibrosis index, Southern Italy

\section{Background}

Hepatocellular carcinoma (HCC) - the fifth most common cancer in men $(554,000$ cases, $7.5 \%$ of the total burden of cancer) and the ninth in women $(228,000$ cases, $3.4 \%$ ) worldwide - represents an important public health issue. The HCC burden is particularly heavy in

\footnotetext{
* Correspondence: serrainod@cro.it

${ }^{\dagger}$ Equal contributors

${ }^{3}$ Unit of Cancer Epidemiology, CRO Aviano National Cancer Institute, Via F.

Gallini 2, 33081 Aviano, (PN), Italy

Full list of author information is available at the end of the article
}

less developed countries, where $83 \%$ of the estimated 782,000 new HCC cases worldwide were diagnosed in 2012 [1]. Within the World Health Organization (WHO) European region, one of the highest HCC incidence rates is registered in southern Italy, mostly because of an epidemic in the Campania region, with yearly rates as high as $48.3 \mathrm{HCC}$ cases/100,000 in men and $18.4 / 100,000$ in women [2-4].

Infection with hepatitis $\mathrm{C}$ virus (HCV) and/or hepatitis $B$ virus (HBV) are major risk factors for $\operatorname{HCC}[5,6]$. Worldwide, the estimated prevalence of $\mathrm{HCV}$ infection 
is about $2.2 \%$, with regional variations ranging from $<1.0 \%$ in northern Europe to $>3 \%$ in northern Africa. Within Europe, the lowest prevalence of HCV infection was reported in the United Kingdom and Scandinavia $(0.01-0.1 \%)$, and the highest one in southern Italy (7.5\%) [6].

In Italy, population-based sero surveys showed a strong North-south geographic gradient [7-10], with high prevalence of $\mathrm{HCV}$ in the southern part of the country. In this area, particularly elevated HCV prevalence rates were recorded among the older segment of the population $(23 \%$ of people aged 65 or more was HCV-positive in a population-based investigation conducted by our study group between 2003 and 2006) [11, 12]. Chronic HCV infection (i.e., HCV RNA-positivity) is more common than chronic HBV infection, and high $\mathrm{HCV}$ prevalence is mainly due to iatrogenic transmission in the past decades [12].

An estimated 55-85\% of people with HCV infection progress to chronic $\mathrm{HCV}$ infection, a condition that puts these people at risk of liver cirrhosis, liver failure or HCC at varying rates according to factors such as age, male sex, presence of other risk factors (e.g., alcohol), or to viral infections and metabolic characteristics [5, 6, 13, 14]. Liver fibrosis is a major negative prognostic marker, and the degree of histologic fibrosis in a liver biopsy sample is still the most common tool for staging liver diseases associated with $\mathrm{HCV}$ and/or HBV infections. However, such diagnostic procedure is affected by several drawbacks, and noninvasive serum markers have been proposed and validated to predict the progression of liver fibrosis, including the FIB-4 index -described in the Methods section [15-17].

In this study, we took advantage of a population-based cohort whose baseline HBV and HCV seroprevalence was evaluated between 2003 and 2006 in the province of Naples, an area of southern Italy covered by a population-based cancer registry and with high incidence rates of HCC [11]. The main aims of this analysis were to estimate incidence and determinants of newly diagnosed HCC cases among the cohort members with special emphasis on the consequences of HCV RNApositivity- and the role of FIB- 4 as an index of hepatic fibrosis in HCC.

\section{Methods}

\section{Study design and population}

The design of this population-based investigation is longitudinal. Our study took place in an area of the province of Naples, southern Italy, with about 650,000 inhabitants who are covered by a population-based cancer registry - the Campania Cancer Registry (CCR).

The enrollment in this population-based seroprevalence survey took place in 2003-2006, when 4496 individuals aged 20 years or older were randomly selected (after stratification for sex and age) from the resident population [11]. At enrolment, study participants were interviewed, blood sample taken and tested for $\mathrm{HCV}$ and HBV infections and for hepatic metabolic activity. Among these 4496 individuals, 336 were anti-HCV positives and 100 were $\mathrm{HBsAg}$-positives, and they were the main target of this follow-up analysis.

\section{Inclusion criteria}

For the aims of this cohort analysis, we excluded four of the 4496 individuals tested in 2003-2006 because they had been already diagnosed with HCC at enrolment (i.e., they were prevalent $\mathrm{HCC}$ cases).

\section{Data collection}

A semi-automated, anonymous record linkage was carried out in October 2014 by means of a previously validated record linkage procedure [18]. We linked the database of the seroprevalence study and the database of the population-based CCR. HCC at CCR were identified according to International Classification of Diseases, 10th revision [19] and International Classification of Diseases for Oncology (ICDO, C22.0-C22.9 codes) [20]. Individual data regarding the occurrence of new $\mathrm{HCC}$ diagnoses and vital status were updated to December 2012 (last date of cancer registration).

Serum alanine transaminase (ALT), aspartate aminotransferase (AST), gamma-glutamyl transferase $(\gamma \mathrm{GT})$, and platelets counts were measured at enrolment with upper normal limits (UNL) of $40 \mathrm{U} / \mathrm{L}$ for AST and ALT; and $30 \mathrm{U} / \mathrm{L}$ for $\gamma \mathrm{GT}$ [11].

To assess liver fibrosis, we used the FIB-4 index, computed according to the following formula [15]: FIB-4= age $\left[\right.$ years] $\times$ AST $[\mathrm{U} / \mathrm{L}] /\left(\right.$ platelets $\left[10^{9} / \mathrm{L}\right] \times \sqrt{ }$ ALT $\left.[\mathrm{U} / \mathrm{L}]\right)$. The FIB- 4 values were divided into three groups/tertiles in order to make our results comparable with those already described in the literature [15-17]: FIB-4 $<1.45$, the lowest tertile, which identifies subjects without liver fibrosis; FIB-4 between 1.45 and 3.25, the intermediate tertile, which identifies subjects with mild to moderate fibrosis; and FIB- $4>3.25$, the highest tertile, which identifies subjects with severe fibrosis.

Among the 4492 individuals included in this cohort analysis, 99 were chronically infected with HBV (i.e., they were $\mathrm{HBsAg-positives);} 243$ were chronically infected with HCV (i.e., they were HCV RNA-positives); and 89 were anti HCV-positives but HCV RNAnegatives. Four individuals $\mathrm{HBsAg}$-positives were also HCV RNA-positives (Fig. 1).

\section{Statistical analysis}

Person-years (PY) at risk of HCC were computed from date of testing to date of HCC diagnosis; date of death or December 31, 2012, whichever occurred first. 


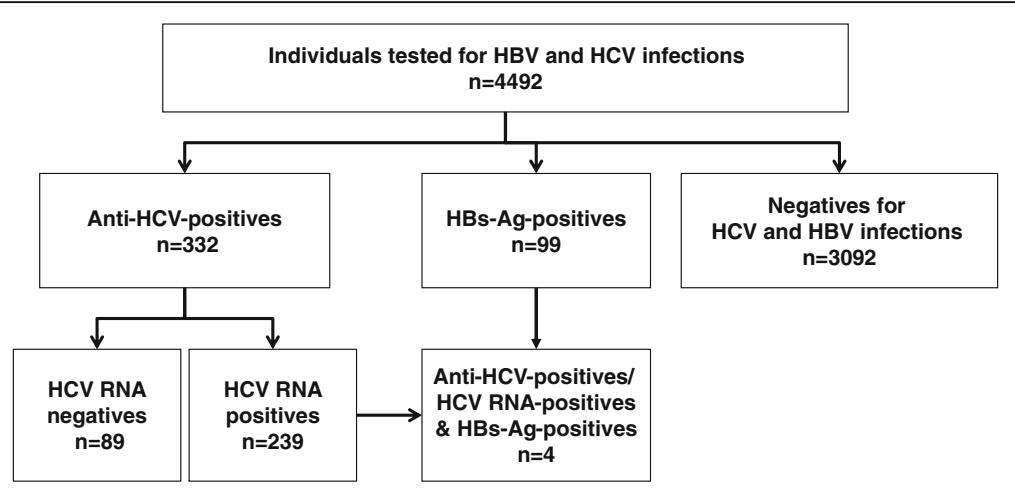

Fig. 1 Distribution of cohort members according to HCV and HBV test results

Incidence rates (IR) of $\mathrm{HCC}$ were computed by dividing the number of new cancers by PY at risk. The association between selected variables, collected at time of testing, and the occurrence of HCC at follow-up was estimated by using the Cox multivariable regression analysis through the calculation of hazard ratios (HR) and $95 \%$ CIs adjusted for sex, age, HBV and HCV infection. The probability of surviving according to $\mathrm{HCV}$ infection was computed according to the Kaplan-Meier method [21].

All statistical analyses were performed using commercially available software (SAS Institute Inc., version 9.4, Cary, NC, USA; and STATA version 13, StataCorp LP, College Station, Texas).

\section{Results}

The 4492 cohort members included in this study (44.7\% men) had a median age of 45.7 years (interquartile range -IQR: $30.5-60.3$ years), and they had been followed up for a median period of 8.0 years (IQR: 7.2-8.6 years). The median time from testing to HCC diagnosis was 37 months, while the median age at HCC diagnosis was 73.3 years (data not shown).

Twenty-two cohort members developed HCC during the 34,749 PYs of follow-up: two were anti HCV-negatives and HBsAg-negatives; 15 were HCV RNA-positives; three were anti HCV-negatives and HBsAg-positives; and two were anti $\mathrm{HCV}$-positives/HCV RNA-negatives and HBsAgnegatives.

Table 1 shows IRs and multivariate HRs for HCC according to selected characteristics collected at baseline. Overall, the IR of HCC was 63.3 cases $/ 10^{5} \mathrm{PY}$, and the cumulative incidence at the end of the follow-up period was $0.5 \%$ (22/4492). Elevated HCC IRs were recorded among subjects aged 60 years or older (252.8/ $10^{5}$ PY in those $\geq 70$ years), in HCV RNA-positives/ HBsAg-negatives (909.3/10 5 PY), and in HBsAg-positive/ HCV-negative individuals $\left(403.3 / 10^{5} \mathrm{PY}\right)$. IRs of HCC were highly increased in cohort members with liver markers exceeding by three or more times the normal level, i.e., $1598 \mathrm{HCC}$ cases $/ 10^{5}$ PY for ALT; 3539 cases $/ 10^{5}$ PY for AST; and 1006 cases $/ 10^{5}$ PY for yGT. Similarly, individuals with the highest tertile of FIB-4 index (i.e., >3.25) showed a very high IR of HCC, 1889 cases $/ 10^{5}$ PY (Table 1). Eighty-nine anti HCV-positive/HCV RNA-negative individuals developed two HCC cases (IR = 296.0, 95 \% CI: 74.0-1184) (data not shown).

At multivariable analysis, statistically significant risk factors for HCC included age $\geq 60$ years, HCV RNApositivity $\quad(H R=61.8), \quad H B s A g$-positivity $\quad(H R=75.0)$, elevated values of markers of hepatic metabolic activity, with elevated risks (highest versus normal level) ranging from 10 -fold for $\gamma \mathrm{GT}$ to 50 -fold for platelet below 220 . Increasing values of FIB-4 index were associated with increasing HCC risks - e.g., the highest FIB- 4 tertile was coupled with a 17.6-fold higher risk of HCC, as compared to cohort members with lower values $(95 \% \mathrm{CI}$ : 6.2-49.7) (Table 1).

The distribution of cohort members according to chronic HCV infection, FIB-4 index and HCC is described in Table 2. HCV infection and FIB-4 index were strongly associated: $59.1 \%$ of individuals with the highest FIB-4 tertile (68/115) were chronically infected with $\mathrm{HCV}$, as compared to $15.4 \%(110 / 714)$ of individuals with the intermediate FIB- 4 tertile, and $1.8 \%$ for those with the lowest FIB-4 tertile. The HR of HCC directly increased with increasing values of FIB-4, in both anti HCV-negatives and in HCV RNA-positives. In anti HCV-negatives, HCC risk was 79-fold elevated (95 \% CI: 4.9-1285) in those with the highest FIB-4 tertile -as compared to the lowest one. Conversely, in HCV RNApositive cohort members, HCC risk was 771-fold higher (95 \% CI: 100-5949) in those with the highest FIB-4 tertile -as compared to the lowest one (Table 2). The highest HCC cumulative incidence $(17.4 \%$ after 4 years of follow-up) was recorded among HCV RNA-positives with the highest FIB-4 tertile (Fig. 2). 
Table 1 Distribution of 4492 study subjects by selected characteristics at enrolment; diagnosis of hepatocellular carcinoma (HCC) at follow-up; HCC incidence rates and hazard ratios for HCC with 95 \% confidence intervals (CI). Naples, 2003-2012

\begin{tabular}{|c|c|c|c|c|}
\hline \multirow[t]{2}{*}{ Characteristics at enrolment } & \multirow{2}{*}{$\begin{array}{l}\text { Study subjects } \\
\text { No. }\end{array}$} & \multirow{2}{*}{$\begin{array}{l}\text { HCC cases } \\
\text { No. }\end{array}$} & \multirow{2}{*}{$\begin{array}{l}\text { Incidence Rate/10 } \\
(95 \% \mathrm{Cl})\end{array}$} & \multirow{2}{*}{$\begin{array}{l}\text { Hazard Ratios } \\
(95 \% \mathrm{Cl})^{\mathrm{b}}\end{array}$} \\
\hline & & & & \\
\hline Total & 4492 & 22 & $63.3(41.7-96.2)$ & \\
\hline \multicolumn{5}{|l|}{ Gender } \\
\hline Female & 2482 & 10 & $51.4(27.6-95.5)$ & $1^{*}$ \\
\hline Male & 2010 & 12 & $78.5(44.6-138.3)$ & $1.2(0.5-2.7)$ \\
\hline \multicolumn{5}{|l|}{ Age at testing (years) } \\
\hline$<60$ & 3349 & 3 & $11.3(3.6-35.0)$ & $1^{*}$ \\
\hline $60-69$ & 551 & 9 & $214.7(111.7-412.6)$ & $7.5(1.8-30.8)$ \\
\hline$\geq 70$ & 592 & 10 & $252.8(136.0-469.8)$ & $6.8(1.6-29.3)$ \\
\hline \multicolumn{5}{|l|}{ Chronic HCV/HBV infections** } \\
\hline Anti HCV-negative/HBsAg-negative & 4065 & 2 & $6.3(0.8-22.8)$ & $1^{*}$ \\
\hline HCV RNA-negative/HBsAg-positive & 95 & 3 & $403.3(83.2-1179)$ & $75.0(12.3-456.5)$ \\
\hline HCV RNA-positive/HBsAg-negative & 239 & 15 & $909.3(509.0-1500)$ & $61.8(13.3-286.4)$ \\
\hline HCV RNA-positive/HBsAg-positive & 4 & 0 & $0.0(0.0-11,938)$ & $0.0(0.0-\infty)$ \\
\hline \multicolumn{5}{|l|}{ Y-glutamyl transferase (YGT) U/L ${ }^{a}$} \\
\hline$\leq 30$ & 3588 & 9 & $32.2(16.8-61.9)$ & $1^{*}$ \\
\hline $31-90$ & 784 & 5 & $83.9(34.9-201.6)$ & $1.5(0.5-4.7)$ \\
\hline$>90$ & 116 & 8 & $1006(503.0-2011)$ & $10.3(3.6-29.2)$ \\
\hline \multicolumn{5}{|l|}{ Alanine transaminase $(A L T) U / L^{a}$} \\
\hline$\leq 40$ & 3954 & 8 & $26.1(13.1-52.2)$ & $1^{*}$ \\
\hline $41-120$ & 490 & 9 & $240.1(125.0-461.5)$ & $4.1(1.5-11.4)$ \\
\hline$>120$ & 45 & 5 & $1598(665-3840)$ & $10.3(3.2-33.3)$ \\
\hline \multicolumn{5}{|l|}{ Aspartate aminotransferase (AST) $U / L^{a}$} \\
\hline$\leq 40$ & 4294 & 6 & $18.0(8.1-40.0)$ & $1^{*}$ \\
\hline $41-120$ & 170 & 11 & 885.1 (490.2-1598) & $9.4(3.1-28.8)$ \\
\hline$>120$ & 25 & 5 & $3539(1473-8501)$ & $27.4(7.6-98.0)$ \\
\hline \multicolumn{5}{|l|}{ Platelet count $\left(10^{3} / \mu l\right)^{a}$} \\
\hline $220-700$ & 2253 & 2 & $11.4(1.4-41.1)$ & $1^{*}$ \\
\hline$<220$ & 2203 & 20 & $118.4(72.3-182.8)$ & $50.0(1.0-100.0)$ \\
\hline \multicolumn{5}{|l|}{$\mathrm{FIB}-4^{\mathrm{a}}$} \\
\hline$<1.45$ & 3552 & 1 & $3.6(0.5-25.4)$ & \multirow{2}{*}{$1^{*}$} \\
\hline $1.45-3.25$ & 774 & 5 & $88.3(36.8-212.2)$ & \\
\hline$>3.25$ & 130 & 16 & $1889(1157-3083)$ & $17.6(6.2-49.7)$ \\
\hline
\end{tabular}

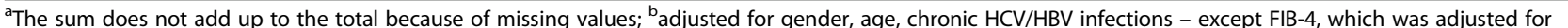
gender and chronic HCV/HBV infections since age is included in the index; *reference category; **89 HCV-positive, RNA-negative study subjects who developed 2 HCC cases were excluded

Furthermore, HCV-infection negatively affected the survival of the cohort members: after 8 years of follow-up, $94.6 \%$ of the $4065 \mathrm{HCV}$-negatives was alive, as compared to $71.5 \%$ of HCV RNA-positive individuals $(p<0.001)$ (Fig. 3).

\section{Discussion}

This population-based cohort study of individuals tested for hepatitis viruses was conducted in an area of southern Italy with one of the highest incidence rates of HCC in Europe [1]. The study findings confirmed that people chronically infected with $\mathrm{HBV}$ (i.e., HBsAgpositive individuals) or $\mathrm{HCV}$ (i.e., anti HCV RNApositive individuals) are at a substantially higher risk of HCC than uninfected ones. In addition, to substantiate the well-established role of $\mathrm{HCV}$ on heightening the risk of HCC, the study findings add further, populationbased evidence to the few studies that have already 
Table 2 Hazard ratios (HR) with $95 \%$ confidence intervals (Cl) for hepatocellular carcinoma (HCC) among 4270 study subjects, according to HCV RNA-positivity and FIB-4 index. Naples, 2003-2012

\begin{tabular}{|c|c|c|c|c|c|c|c|c|c|}
\hline \multirow{2}{*}{$\begin{array}{l}\mathrm{HCV} \\
\text { RNA }\end{array}$} & \multicolumn{3}{|c|}{ FIB-4 <1.45 } & \multicolumn{3}{|c|}{ FIB-4 1.45-3.25 } & \multicolumn{3}{|c|}{ FIB-4 >3.25 } \\
\hline & $\begin{array}{l}\text { Subjects } \\
\text { No. }\end{array}$ & $\begin{array}{l}\text { HCC cases } \\
\text { No. }(\%)\end{array}$ & $\mathrm{HR}^{\mathrm{b}}(95 \% \mathrm{Cl})$ & $\begin{array}{l}\text { Subjects } \\
\text { No. }\end{array}$ & $\begin{array}{l}\text { HCC cases } \\
\text { No. }(\%)\end{array}$ & $\mathrm{HR}^{\mathrm{b}}(95 \% \mathrm{Cl})$ & $\begin{array}{l}\text { Subjects } \\
\text { No. }\end{array}$ & $\begin{array}{l}\text { HCC cases } \\
\text { No. }(\%)\end{array}$ & $\mathrm{HR}^{\mathrm{b}}(95 \% \mathrm{Cl})$ \\
\hline Negative & 3380 & $1(0.03)$ & $1^{*}$ & 604 & $0(0.0)$ & $0(0-\infty)$ & 47 & $1(2.1)$ & $79.5(4.9-1285)$ \\
\hline Positive & 61 & $0(0.0)$ & $0(0-\infty)$ & 110 & $3(2.7)$ & 99.5 (10.3-957.3) & 68 & $12(17.6)$ & $771.2(100.0-5949)$ \\
\hline
\end{tabular}

a9 HBsAg-positive and 89 anti-HCV-positive, HCV-RNA-negative study subjects were excluded. Information on FIB-4 index was not available for 34 remaining study subjects

${ }^{\mathrm{b}}$ Hazard ratios adjusted for gender

*Reference category

documented the prognostic value of the FIB- 4 index as a non-invasive screening tool for HCC.

Early detection of HCC has remarkable survival advantages, and the efficacy of HCC screening is a matter of debate with particular regard to the role of non-invasive screening tools as alternative to, or in combination with, liver biopsy and fibroscan [22, 23]. A recent metaanalysis of studies carried out in patients with chronic HBV infection highlighted a modest diagnostic accuracy and sensitivity of the FIB-4 index for predicting liver fibrosis in these patients [24]. Conversely, in a cohort study involving 986 Korean HBsAg carriers, the FIB-4 index was shown to have a valuable role in HCC screening, as HBsAg carriers with high FIB-4 index were at very high risk of HCC [25]. High levels of FIB-4 were also significantly predictive of HCC among moderate or heavy alcohol drinkers [26], and among HIV-infected patients [27].

The FIB-4 index was firstly proposed to assess the presence of liver fibrosis in patients with $\mathrm{HCV} / \mathrm{HIV}$ coinfection [28] and, subsequently, it was validated in a cohort of HCV-infected patients in France [15], and in a large cohort in the United States. FIB-4 was shown to be a valid parameter for staging liver disease and monitoring HCV-infected patients in longitudinal studies [16]. Since advanced fibrosis is among the most important indicators in stratifying patients with chronic $\mathrm{HCV}$ infection for retreatment, Tanwar and colleagues [29] compared the performance of ten biomarkers of fibrosis among patients with chronic $\mathrm{HCV}$ and treatment failure. They assessed the impact on biomarker performance of two different assays of hyaluronic acid. Although many biomarkers exhibited good diagnostic performance for the detection of advancing fibrosis, the study findings highlighted a potential drawback, since the diagnostic performance was significantly affected by the selection of individual component assays [29].

In the French cohort, FIB-4 values lower than 1.45 had a negative prognostic value of $94.7 \%$ of excluding a severe fibrosis, while a value higher than 3.25 had a positive predictive value of $82.1 \%$ [15]. Accordingly, the findings from this cohort study highlighted that individuals with a value
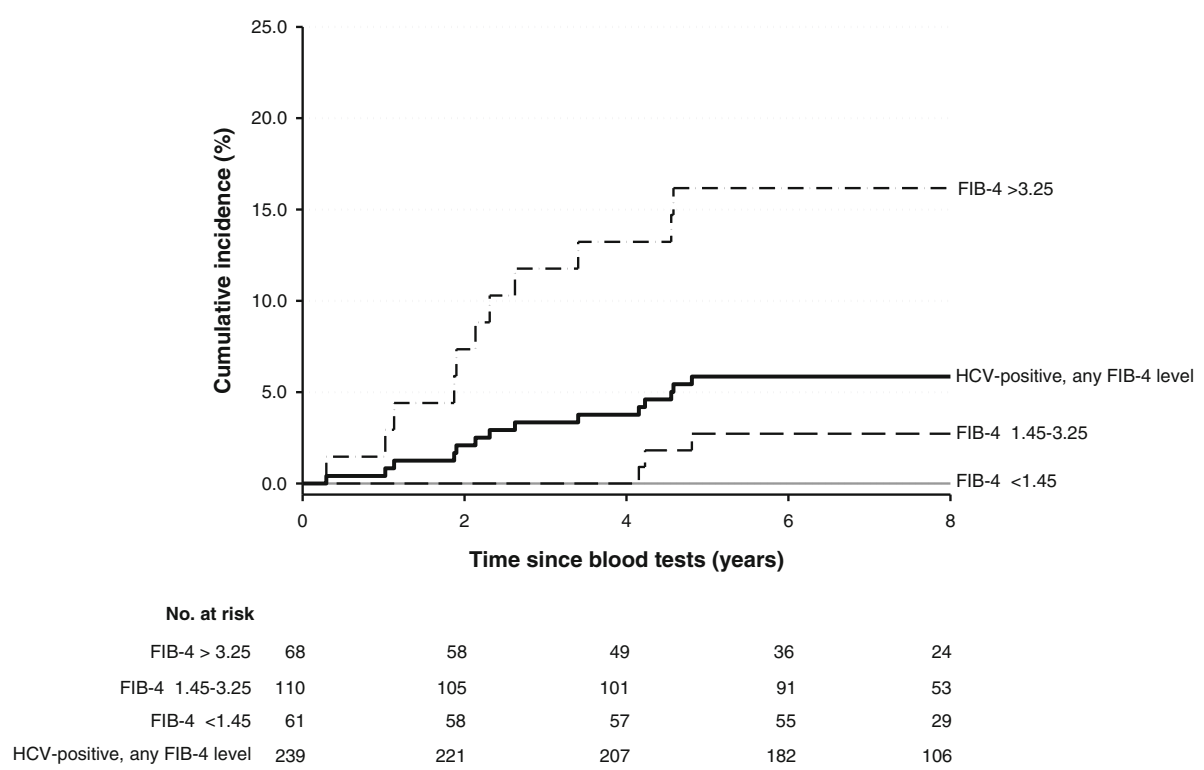

$\begin{array}{rr}58 & 49 \\ 105 & 101 \\ 58 & 57 \\ 221 & 207\end{array}$

$\begin{array}{rr}36 & 24 \\ 91 & 53 \\ 55 & 29 \\ 182 & 106\end{array}$

Fig. 2 Incidence of hepatocellular carcinoma among HCV RNA-positive/HBsAg-negative subjects 


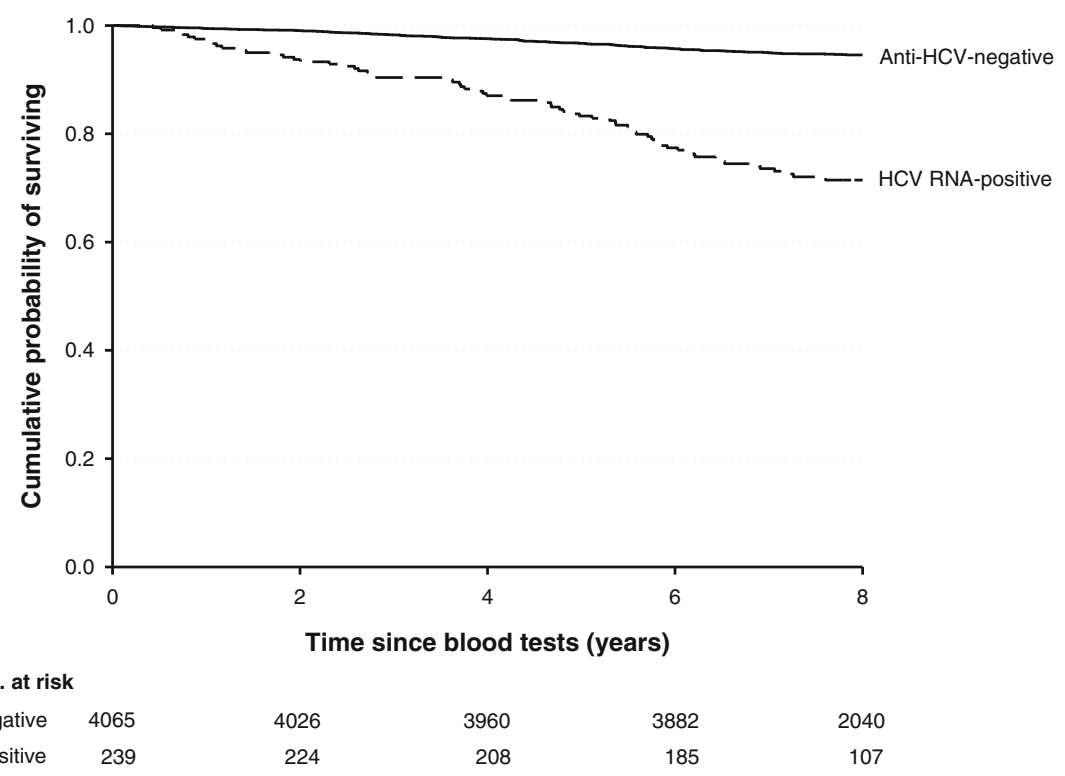

Fig. 3 Cumulative survival probability by chronic HCV infection among 4304 study subjects. Naples, 2003-2012. * 99 HBsAg-positive and 89 HCVpositive, HCV-RNA-negative study subjects were excluded

of FIB-4 index higher than 3.25 were at a 17 -fold elevated HCC risk - as compared to those with lower values of FIB-4. In particular, the highest HCC incidence was recorded among chronically HCV-infected cohort members with the highest FIB-4 tertile. An increased incidence of HCC was also noted in individuals with intermediate FIB4 tertile, thus our findings point to a significant predictive role of FIB-4 in identifying individuals at high risk of HCC.

In the area where the present study was conducted, more than $90 \%$ of HCC cases were attributable to HCV and/or HBV infections, and the remaining to alcohol intake (6\%), smoking or other risk factors [30]. Accordingly, only two of the $22 \mathrm{HCC}$ cases documented in this cohort were not chronically infected with $\mathrm{HCV}$ or $\mathrm{HBV}$, whereas 15 were $\mathrm{HCV}$ chronic carriers and HBs-Agnegative.

In areas with high prevalence rates of $\mathrm{HCV}$ infection, as the one where this cohort study was carried out, the FIB-4 index of fibrosis seems to significantly improve the early identification of individuals at higher risk of developing $\mathrm{HCC}$. From this perspective, it is worth noting that the time from FIB-4 measurement and HCC diagnosis decreased from 6.8 years in the HCC case with FIB- 4 value $<1.45$, to a median of 2.8 years among $\mathrm{HCC}$ cases with a FIB-4 value higher than 3.25.

The rapid development of direct-acting antiviral (DAA) agents for HCV infection has driven substantial optimism on new therapeutic interventions, with regard to improved efficacy, lower frequency of side effects, and shorter duration than currently available therapies.
However, the potential effect of these new therapies is limited because of lack of systematic screening for $\mathrm{HCV}$ infection and the high cost of DAA. Among the members of this cohort, at time of testing less than half ( $n=$ 149 ) of the $332 \mathrm{HCV}$-infected individuals was aware of being infected, and only 42 of them (28.2 \%) had already received conventional interferon-based treatment. Given the costs of DAA, there is heated debate on how to prioritize patients to be treated with these drugs, with European guidelines suggesting to privilege patients with advanced liver disease for DAA therapies [31]. The findings from this study may further help in addressing this issue, by suggesting that people with chronic $\mathrm{HCV}$ infection with a value of FIB-4 index $>3.25$ are at elevated risk of developing $\mathrm{HCC}$ in the next 4 years. Furthermore, people with chronic $\mathrm{HCV}$ infection with a value of FIB-4 index $\geq 1.45$ are at elevated risk of developing $\mathrm{HCC}$ in the next 5-6 years.

It is worth stressing that these results derive from about 8 years of follow-up of 4492 people living in an area of southern Italy covered by a population-based cancer registry - the CCR [32]. Completeness and accuracy in the ascertainment of HCC cases occurring in the cohort was thus ensured by the longitudinal study design. Lack of information, at baseline, on some variables known to be associated with HCC risk (e.g., alcohol intake), or at follow-up on determinants of progression of liver disease (e.g., HCV treatment) needs to be mentioned. Furthermore, a relative small number of events limited the statistical power of sub-group analysis. Moreover, it was not feasible to estimate HCC risk 
in $\mathrm{HBsAg}$-positives and in anti $\mathrm{HCV}$-positive/ $\mathrm{HCV}$ RNA-negative individuals because of a reduced statistical power due to a small number of HCC diagnoses ( $n=3$, and $n=2$-respectively).

In addition to the above discussed impact of $\mathrm{HCV}$, HBV and FIB-4 index of fibrosis, our findings from the multivariable analysis confirmed the prognostic indication associated with other well established predictors of HCC. Values of ALT, AST, and $\gamma$ GT higher than normal were indeed associated with high risks of $\mathrm{HCC}$ even after adjustment for HCV infection, HBV infection and FIB-4 index.

\section{Conclusions}

Although the standard method to assess hepatic fibrosis in chronic hepatitis remains the histologic staging of liver biopsy specimen, findings from this populationbased cohort study support the results of the few studies that have already documented a predictive role of FIB-4 index of fibrosis for HCC occurrence. This effect was particularly evident in people with chronic $\mathrm{HCV}$ infection, thus offering new insights for identifying people at high HCC risk worth to be prioritized for receiving anti$\mathrm{HCV}$ treatments.

\section{Abbreviations}

ALT: Alanine transaminase; AST: Aspartate aminotransferase; CCR: Campania Cancer Registry; Cl: Confidence intervals; DAA: Direct-acting antiviral; HBV: Hepatitis B virus; HCC: Hepatocellular carcinoma; HCV: Hepatitis C virus; HR: Hazard ratios; IR: Incidence rates; PY: Person-years; UNL: Upper norma limit; үGT: Gamma-glutamyl-transferase

\section{Acknowledgements}

The authors thank Ms. Luigina Mei for editorial assistance.

\section{Funding}

This study was supported by grants from: Associazione Italiana per la Ricerca sul Cancro, Milan, Italy (Grant No. 8942); International Agency for Cancer Research, Lyon, France; Ricerca Corrente IRCCS Centro di Riferimento Oncologico, Aviano, Italy and IRCCS Istituto Nazionale per le Malattie Infettive L. Spallanzani, Rome, Italy.

\section{Availability of data and material}

The datasets during and/or analysed during the current study is available from the corresponding author on a reasonable request.

\section{Authors' contributions \\ MF, DS, PP designed the study and performed the literature review, supervised statistical analysis and interpretation of data and drafted the manuscript; EG, PDP, PS, SF contributed to the study design and drafting of the manuscript; DV, SV, LDM performed the first statistical analyses; PDC, VC, MDO performed the lab tests; DS, LDM, PP, SF refined and performed the final statistical analysis, contributed to the study design and drafting of the manuscript. All authors critically revised the manuscript for intellectual and significant contents and approved the final manuscript for submission.}

\section{Authors' information}

Mario Fusco, MD, head of the Campania Cancer Registry; Pierluca Piselli, MSc, epidemiologist; Saverio Virdone, MSc, statistician; Pietro Di Cicco, MD, microbiologist; Paola Scognamiglio, MD, infectious disease specialist; Paolo De Paoli, MD, Scientific Director; Valerio Ciullo, MSc, statistician; Enrico Girardi, MD, epidemiologist; Diana Verdirosi, MSc, biologist; Michele D'Orazio, MD, immunologist; Luigino Dal Maso, PhD, statistician; Silvia Franceschi, MD, epidemiologist, head of research unit; Diego Serraino, MD, cance epidemiologist, head of research unit.

\section{Competing interests}

The authors declare that they have no competing interests.

\section{Ethics approval and consent to participate}

The study protocol conformed to the 1975 Declaration of Helsinki and had been approved by the by the Board of Ethics of the Local Health Authority (i.e., the former Public Health Authority ASL Napoli 4).

\section{Author details}

${ }^{1}$ Registro Tumori, ASL Napoli-3 Sud, Brusciano, Napoli, Italy. ${ }^{2}$ Clinical Epidemiology Unit, National Institute for Infectious Diseases "L. Spallanzani", Rome, Italy. ${ }^{3}$ Unit of Cancer Epidemiology, CRO Aviano National Cancer Institute, Via F. Gallini 2, 33081 Aviano, (PN), Italy. ${ }^{4}$ Azienda Sanitaria Locale (ASL) Napoli 3, Brusciano, Napoli, Italy. ${ }^{5}$ Scientific Directorate, CRO Aviano National Cancer Institute, Via F. Gallini 2, 33081 Aviano, (PN), Italy.

${ }^{6}$ International Agency for Research on Cancer, Lyon, France.

Received: 22 August 2016 Accepted: 17 October 2016

Published online: 03 November 2016

\section{References}

1. Ferlay J, Soerjomataram I, Ervik M, Dikshit R, Eser S, Mathers C, et al. GLOBOCAN 2012 V1.0, Cancer incidence and mortality worldwide: IARC Cancer Base No. 11 (Internet). Lyon, France: International Agency for Research on Cancer; 2013. Available at: http://globocan.iarc.fr. Accessed 15 Oct 2016.

2. AIRTUM ITACAN. Tumori in Italia, Versione 2.0. Associazione Italiana dei Registri TUMori ( http://www.registri-tumori.it ). Accessed 15 Oct 2016.

3. Polilli E, Tontodonati M, Flacco ME, Ursini T, Striani P, Di Giammartino D, et al. High seroprevalence of HCV in the Abruzzo Region, Italy: results on a large sample from opt-out pre-surgical screening. Infection. 2016;44:85-91.

4. Montella M, Crispo A, Grimaldi M, Angeletti C, Amore A, Ronga D, et al. Prevalence of hepatitis $C$ virus infection in different population groups in southern Italy. Infection. 2005;33:9-12.

5. El-Serag HB. Hepatocellular carcinoma. N Engl J Med. 2011;365:1118-27.

6. IARC Working Group on the Evaluation of Carcinogenic Risks to Humans. A review of human carcinogens. Part B: biological agents. IARC monographs on the evaluation of carcinogenic risks to humans. Lyon: IARC; 2012.

7. Di Stefano R, Stroffolini T, Ferraro D, Usticano A, Valenza LM, Montalbano L, et al. Endemic hepatitis $C$ virus infection in a Sicilian town: further evidence for iatrogenic transmission. J Med Virol. 2002;67:339-44.

8. Guadagnino V, Stroffolini T, Rapicetta M, Costantino A, Kondili LA, MennitiIppolito $F$, et al. Prevalence, risk factors, and genotypes distribution of hepatitis $C$ virus infection in the general population: a community- based survey in southern Italy. Hepatology. 1997;26:1006-11.

9. Maio G, D'Argenio P, Stroffolini T, Bozza A, Sacco L, Tosti ME, et al. Hepatitis $C$ virus infection and alanine transaminase levels in the general population: a survey in a southern Italian town. J Hepatol. 2000;33:116-20.

10. Pendino GM, Mariano A, Surace P, Caserta CA, Fiorillo MT, Amante A, et al. Prevalence and etiology of altered liver tests: a population-based survey in a Mediterranean town. Hepatology. 2005;41:1151-9.

11. Fusco M, Girardi E, Piselli P, Palombino R, Polesel J, Maione C, et al. Epidemiology of viral hepatitis infections in an area of southern Italy with high incidence rates of liver cancer. Eur J Cancer. 2008;44:847-53.

12. Guadagnino V, Stroffolini T, Caroleo B, Menniti Ippolito F, Rapicetta M, Ciccaglione $A R$, et al. Hepatitis $C$ virus infection in an endemic area of Southern Italy 14 years later: evidence for a vanishing infection. Dig Liver Dis. 2013:45:403-7.

13. Perz JF, Armstrong GL, Farrington LA, Hutin YJ, Bell BP. The contributions of hepatitis $B$ virus and hepatitis $C$ virus infections to cirrhosis and primary liver cancer worldwide. J Hepatol. 2006;45:529-38.

14. Hajarizadeh B, Grebely J, Dore GJ. Epidemiology and natural history of HCV infection. Nat Rev Gastroenterol Hepatol. 2013;10:553-62.

15. Vallet-Pichard A, Mallet V, Nalpas B, Verkarre V, Nalpas A, Dhalluin-Venier V, et al. FIB-4: an inexpensive and accurate marker of fibrosis in HCV infection. Comparison with liver biopsy and fibrotest. Hepatology. 2007;46:32-6. 
16. Holmberg SD, Lu M, Rupp LB, Lamerato LE, Moorman AC, Vijayadeva V, et al. Noninvasive serum fibrosis markers for screening and staging chronic hepatitis C virus patients in a large US cohort. Clin Infect Dis. 2013;57:240-6.

17. de Lucca Schiavon L, Narciso-Schiavon JL, de Carvalho-Filho RJ. Noninvasive diagnosis of liver fibrosis in chronic hepatitis C. World J Gastroenterol. 2014;20:2854-66.

18. Dal Maso L, Braga C, Franceschi S. Methodology used for "software for automated linkage in Italy" (SALI). J Biomed Inform. 2001;34:387-95 [Description of upgraded version of SALI software at: http://www.registritumori.it/PDF/AIRTUM2009HANDBOOK/Chapter_Appendix2.pdf].

19. Percy C, Van Holten V, Muir C, editors. International classification of diseases for oncology. 2nd ed. Geneva: World Health Organization; 1990.

20. Fritz A, Percy C, Jack A, Shanmugaratnam K, Sobin L, Parkin DM, et al., editors. International classification of diseases for oncology. 3rd ed. Geneva: World Health Organization; 2000.

21. Breslow NE, Day NE. Statistical methods in cancer research, Vol. II: the design and analysis of cohort studies. IARC Sci Publ No. 82. IARC: Lyon; 1987.

22. Martínez SM, Crespo G, Navasa M, Forns X. Noninvasive assessment of liver fibrosis. Hepatology. 2011;53:325-35.

23. De Masi S, Tosti ME, Mele A. Screening for hepatocellular carcinoma. Dig Liver Dis. 2005;37:260-8.

24. Xiao G, Yang J, Yan L. Comparison of diagnostic accuracy of aspartate aminotransferase to platelet ratio index and fibrosis-4 index for detecting liver fibrosis in adult patients with chronic hepatitis B virus infection: a systemic review and meta-analysis. Hepatology. 2015;61:292-302.

25. Suh B, Park S, Shin DW, Yun JM, Yang HK, Yu SJ, et al. High liver fibrosis index FIB-4 is highly predictive of hepatocellular carcinoma in chronic hepatitis B carriers. Hepatology. 2015;61:1261-8.

26. Suh B, Yun JM, Park S, Shin DW, Lee TH, Yang HK, et al. Prediction of future hepatocellular carcinoma incidence in moderate to heavy alcohol drinkers with the FIB-4 liver fibrosis index. Cancer. 2015;121:3818-25.

27. Park LS, Tate JP, Justice AC, Lo Re 3rd V, Lim JK, Bräu N, et al. FIB-4 index is associated with hepatocellular carcinoma risk in HIV-infected patients. Cancer Epidemiol Biomarkers Prev. 2011;20:2512-7.

28. Sterling RK, Lissen E, Clumeck N, Sola R, Correa MC, Montaner J, et al. Development of a simple noninvasive index to predict significant fibrosis in patients with HIV/HCV coinfection. Hepatology. 2006:43:1317-25.

29. Tanwar S, Trembling PM, Hogan BJ, Parkes J, Harris S, Grant P, et al. Biomarkers of hepatic fibrosis in chronic hepatitis $\mathrm{C}$ : a comparison of 10 biomarkers using 2 different assays for hyaluronic acid. J Clin Gastroenterol. 2016; [Epub ahead of print].

30. Franceschi S, Montella M, Polesel J, La Vecchia C, Crispo A, Dal Maso L, et al. Hepatitis viruses, alcohol, and tobacco in the etiology of hepatocellular carcinoma in Italy. Cancer Epidemiol Biomarkers Prev. 2006;15:683-9.

31. European Association for the Study of the Liver. EASL recommendations on treatment of hepatitis C, 2014. Available at: http://files.easl.eu/easlrecommendations-on-treatment-of-hepatitis-C.pdf. Accessed 15 Oct 2016

32. Forman D, Bray F, Brewster DH, Gombe Mbalawa C, Kohler B, Pneros M, et al., editors. Cancer incidence in five continents, Vol. X. IARC Sci Publ No. 164. Lyon: International Agency for Research on Cancer; 2014. p. 744-5.

\section{Submit your next manuscript to BioMed Central and we will help you at every step:}

- We accept pre-submission inquiries

- Our selector tool helps you to find the most relevant journal

- We provide round the clock customer support

- Convenient online submission

- Thorough peer review

- Inclusion in PubMed and all major indexing services

- Maximum visibility for your research

Submit your manuscript at www.biomedcentral.com/submit

) Biomed Central 